\title{
Complement component 5 contributes to poor disease outcome in humans and mice with pneumococcal meningitis
}

\author{
Bianca Woehrl, ${ }^{1}$ Matthijs C. Brouwer, ${ }^{2,3}$ Carmen Murr, ${ }^{1}$ Sebastiaan G.B. Heckenberg, ${ }^{2}$ Frank Baas, ${ }^{4}$ \\ Hans W. Pfister, ${ }^{1}$ Aeilko H. Zwinderman, ${ }^{5}$ B. Paul Morgan, ${ }^{6}$ Scott R. Barnum, ${ }^{7}$ Arie van der Ende, ${ }^{3,8}$ \\ Uwe Koedel, ${ }^{1,3}$ and Diederik van de Beek ${ }^{2,3}$

\begin{abstract}
1Department of Neurology, Klinikum Grosshadern, Ludwig Maximilians University, Munich, Germany. 2Department of Neurology, Center of Infection and Immunity Amsterdam (CINIMA), ${ }^{3}$ ESCMID Meningitis Study Group, ${ }^{4}$ Department of Genome Analysis, and ${ }^{5}$ Department of Biostatistics, Academic Medical Center, Amsterdam, the Netherlands. ${ }^{6}$ Department of Infection, Immunity, and Biochemistry, Cardiff University School of Medicine, Cardiff, Wales, United Kingdom. ${ }^{7}$ Department of Microbiology, University of Alabama, Birmingham, Alabama, USA. ${ }^{8}$ Department of Medical Microbiology
\end{abstract} \\ and The Netherlands Reference Laboratory for Bacterial Meningitis (NRLBM), CINIMA, Academic Medical Center, Amsterdam, the Netherlands.
}

\begin{abstract}
Pneumococcal meningitis is the most common and severe form of bacterial meningitis. Fatality rates are substantial, and long-term sequelae develop in about half of survivors. Disease outcome has been related to the severity of the proinflammatory response in the subarachnoid space. The complement system, which mediates key inflammatory processes, has been implicated as a modulator of pneumococcal meningitis disease severity in animal studies. Additionally, SNPs in genes encoding complement pathway proteins have been linked to susceptibility to pneumococcal infection, although no associations with disease severity or outcome have been established. Here, we have performed a robust prospective nationwide genetic association study in patients with bacterial meningitis and found that a common nonsynonymous complement component 5 (C5) SNP (rs17611) is associated with unfavorable disease outcome. C5 fragment levels in cerebrospinal fluid (CSF) of patients with bacterial meningitis correlated with several clinical indicators of poor prognosis. Consistent with these human data, C5a receptor-deficient mice with pneumococcal meningitis had lower CSF wbc counts and decreased brain damage compared with WT mice. Adjuvant treatment with C5-specific monoclonal antibodies prevented death in all mice with pneumococcal meningitis. Thus, our results suggest $\mathrm{C5}$-specific monoclonal antibodies could be a promising new antiinflammatory adjuvant therapy for pneumococcal meningitis.
\end{abstract}

\section{Introduction}

Community-acquired bacterial meningitis continues to exact a heavy toll, even in developed countries, despite the implementation of childhood vaccination programs and effective antimicrobial agents $(1,2)$. The most common etiologic agents of bacterial meningitis are Streptococcus pneumoniae and Neisseria meningitidis, with the first bacterium responsible for two-thirds of cases in Europe and the United States (1). The fatality rates in patients with meningitis caused by these microorganisms are substantial, at $26 \%$ and $9 \%$, respectively (3), and long-term sequelae, including hearing loss, focal neurological deficit, and cognitive impairment, develop in about half of survivors (1).

Experimental animal models have shown that outcome in bacterial meningitis is related to the severity of inflammation in the subarachnoid space, and it was suggested that outcome could be improved by modulation of the inflammatory response, for example, with dexamethasone (4). Many randomized clinical trials of dexamethasone in bacterial meningitis have been performed, but results have remained ambiguous (5-8). An individual patient data meta-analysis of 5 large recent trials showed no effect of dexamethasone (7). A prospective cohort study showed a decrease in mortality from $30 \%$ to $20 \%$ in adults with pneumococcal meningitis after

Authorship note: Bianca Woehrl and Matthijs C. Brouwer, as well as Uwe Koedel and Diederik van de Beek, contributed equally to this work.

Conflict of interest: The authors have declared that no conflict of interest exists. Citation for this article: J Clin Invest. 2011;121(10):3943-3953. doi:10.1172/JCI57522. nationwide implementation of dexamethasone in the Netherlands (9). New adjunctive therapies are needed to improve the prognosis of bacterial meningitis.

Genetic association studies may reveal new targets for adjuvant therapies (10). Genetic defects in the complement system have been studied in patients with extreme phenotypes of meningitis, particularly those with familial or recurrent disease, focusing on susceptibility to invasive pneumococcal and meningococcal disease (11). The complement system can be divided into 3 activation pathways (the classical, lectin, and alternative pathways), which all converge on a common terminal pathway (12). An essential step in the classical and lectin pathways is cleavage of complement component C2 into its fragments, $\mathrm{C} 2 \mathrm{a}$ and $\mathrm{C} 2 \mathrm{~b}$. A retrospective study, including 40,000 patients with suspected complement deficiency, identified 40 individuals with $\mathrm{C} 2$ deficiency due to a 28-bp deletion (13). A history of invasive infections, mainly pneumococcal infections, was found in 23 (58\%) of these individuals (13). The formation of the alternative pathway $\mathrm{C} 3$ convertase complex $(\mathrm{C} 3 \mathrm{bBb})$ is a crucial step in the alternative pathway and requires complement factor D (fD) (12). fD deficiency due to uncommon SNPs has been described in cases and families with meningococcal and pneumococcal infections $(14,15)$. C3bBb is stabilized by properdin (16), and properdin deficiency predisposes to meningococcal disease due to serogroups W135 and Y; one-third of patients with meningococcal disease caused by these serotypes are properdin deficient. The common terminal pathway consists of complement components C5-C9, and activation forms the anaphylatoxin $\mathrm{C} 5 \mathrm{a}$, a strong proinflam- 


\section{Table 1}

Clinical characteristics of 439 patients with community-acquired bacterial meningitis ${ }^{A}$

\begin{tabular}{|c|c|}
\hline Characteristic & Value/total \\
\hline Age (yr) & $56 \pm 18$ \\
\hline Male sex (no. [\%]) & $208(47 \%)$ \\
\hline Duration of symptoms $<24 \mathrm{~h}$ & $200 / 436(46 \%)$ \\
\hline Pretreatment with antibiotics & $51 / 433(12 \%)$ \\
\hline Predisposing conditions & $253 / 436(58 \%)$ \\
\hline Otitis or sinusitis & $156 / 436(36 \%)$ \\
\hline Pneumonia & $57 / 436(13 \%)$ \\
\hline Immunocompromise & $96 / 436(22 \%)$ \\
\hline \multicolumn{2}{|l|}{ Symptoms and signs on presentation ${ }^{B}$} \\
\hline Headache & $304 / 394(86 \%)$ \\
\hline Neck stiffness & $325 / 421(77 \%)$ \\
\hline Systolic blood pressure (mmHg) & $145 \pm 29$ \\
\hline Heart rate (bpm) & $99 \pm 21$ \\
\hline Body temperature $\left({ }^{\circ} \mathrm{C}\right)$ & $38.7 \pm 1.3$ \\
\hline Score on Glasgow Coma Scalec & $11 \pm 3$ \\
\hline$<8$ indicating coma & $58 / 434(13 \%)$ \\
\hline Focal neurologic deficits & $140 / 436(32 \%)$ \\
\hline \multicolumn{2}{|l|}{ Indexes of CSF inflammation ${ }^{D}$} \\
\hline Opening pressure $\left(\mathrm{mmH}_{2} \mathrm{O}\right)$ & $387 \pm 126$ \\
\hline wbc count $\left(/ \mathrm{mm}^{3}\right)$ & $6,708 \pm 11,964$ \\
\hline wbc count $<1,000 / \mathrm{mm}^{3}$ & $116 / 409(28 \%)$ \\
\hline Protein $(g / l)$ & $4.3 \pm 3.1$ \\
\hline CSF blood glucose ratio & $0.15 \pm 0.16$ \\
\hline Positive blood cultures & $273 / 365(75 \%)$ \\
\hline \multicolumn{2}{|l|}{ Complications } \\
\hline Cardiorespiratory failure & $118 / 420(28 \%)$ \\
\hline Focal neurologic deficits & $86 / 425(20 \%)$ \\
\hline Cerebral infarction & $50 / 436(11 \%)$ \\
\hline \multicolumn{2}{|l|}{ Score on GOS } \\
\hline 1 - death & $35 / 435(8 \%)$ \\
\hline 2 - vegetative state & $1 / 435(0.2 \%)$ \\
\hline 3 - severe disability & $15 / 435(3 \%)$ \\
\hline 4 - moderate disability & $55 / 435(13 \%)$ \\
\hline 5 - good recovery & $329 / 435(76 \%)$ \\
\hline
\end{tabular}

${ }^{A}$ Data are number/number evaluated (percentage), and continuous data are mean \pm SD. BSystolic blood pressure was evaluated in 426 patients, heart rate was evaluated in 421 patients, and temperature was evaluated in 432 patients. 'Score on the Glasgow Coma Scale was evaluated in 434 patients. ${ }^{D}$ CSF opening pressure was evaluated in 151 patients, CSF wbc count was evaluated in 409 patients, CSF protein was evaluated in 412 patients, and CSF blood glucose ratio was evaluated in 408 patients.

matory mediator, and the membrane attack complex (MAC), which creates pores in the bacterial cell wall (12). Deficiencies in these late complement components have been recognized as a cause of recurrent and familial meningococcal infections.

Case-control studies subsequently assessed the effect of SNPs in complement genes on susceptibility to pneumococcal and meningococcal disease in the general population (11). A meta-analysis of studies on 3 SNPs in mannose-binding lectin showed an association of homozygosity for variant alleles with pneumococcal invasive disease (odds ratio [OR], 2.58; 95\% CI, 1.38-4.80) (11). This soluble pattern recognition molecule activates the lectin pathway upon binding to microorganisms (12). Factor $\mathrm{H}(\mathrm{fH})$ regulates the alternative pathway by inactivating $\mathrm{C} 3 \mathrm{bBb}(12)$. The $\mathrm{fH}-496 \mathrm{C} / \mathrm{C}$ genotype was found to be associated with meningococcal disease (OR, 2.0;
95\% CI, 1.3-3.2) (17). Most of the candidate gene approach studies lacked power to detect true associations (11). Recently, a genomewide association study (GWAS) on host susceptibility to meningococcal disease identified a locus in the complement factor $\mathrm{H}$ $(\mathrm{CFH})$ region, providing the first convincing evidence for a role of SNPs in complement genes in susceptibility to infections (18). Little is known about the role of complement SNPs in bacterial meningitis, and so far no associations with disease severity or outcome have been reported in case-control studies for complement SNPs or GWAS (11).

Studies in animal models have provided evidence for involvement of the complement system in modulating severity of pneumococcal meningitis. In rabbits depleted of C3 by administering cobra venom factor, intracisternal inoculation of $S$. pneumoniae resulted in higher bacterial titers in the cerebrospinal fluid (CSF) than in complement-sufficient control animals (19). Other studies showed an increased pneumococcal outgrowth in the brain and blood in gene-targeted mice lacking $\mathrm{C} 1 \mathrm{q}$, affecting only the classical pathway; C3, affecting all complement activation pathways; or the receptor for the opsonin C3b/iC3b (CR3) (20, 21). C3 deficiency led to diminished brain inflammation, paralleled by an attenuation of intracranial complications. However, the lack of CR3-mediated opsonophagocytosis resulted in increased bacteremia that worsened outcome. These data provide evidence that the complement system is important in bacterial meningitis and that antagonizing the detrimental proinflammatory effects of the complement system without inhibiting its antimicrobial activity might be a promising adjuvant therapy option.

We performed a prospective nationwide genetic association study in patients with community-acquired bacterial meningitis to investigate the roles of common genetic variants in the complement system in outcome. By analyzing clinical data and CSF, we identified the potential impact and functionality of a SNP that was associated with outcome. We than validated and explored our findings in an animal model of pneumococcal meningitis and investigated whether adjuvant treatment with a monoclonal antibody targeted against this specific complement component could improve outcome.

\section{Results}

Nationwide prospective cohort study of adults with community-acquired bacterial meningitis. In a prospective nationwide cohort study, we included 642 out of 762 (84\%) identified episodes of communityacquired CSF culture-proven bacterial meningitis in 636 patients. The distribution of causative bacteria was $S$. pneumoniae in 468 (73\%), N. meningitidis in 80 (13\%), and other bacteria in $94(15 \%)$ episodes. DNA samples were obtained from 439 patients $(68 \%)$ and 302 controls. Controls were patients' partners or nonrelated proxies living in the same dwelling, as household members they had similar exposure to bacteria through nasopharyngeal colonization, and were matched for age, ethnicity, and sex (ref. 22 and Supplemental Table 1; supplemental material available online with this article; doi:10.1172/JCI57522DS1). Predisposing conditions, most commonly otitis media or sinusitis (36\%) and immunocompromised state (22\%), were present in $58 \%$ of episodes (Table 1 ). In $13 \%$ of episodes, patients were comatose on admission, and $32 \%$ of the episodes had focal neurologic deficits. The case fatality rate was $8 \%$, and $24 \%$ of the episodes had an unfavorable outcome, defined as a score of 1 through 4 on the Glasgow Outcome Scale (GOS) (23). Patients for whom DNA was obtained were on average 


\section{Table 2}

Genotyping analysis of 17 common complement component polymorphisms in 329 patients with bacterial meningitis with favorable outcome and 105 with unfavorable outcome

\begin{tabular}{|c|c|c|c|c|c|c|c|c|c|c|c|c|c|c|}
\hline \multirow[t]{2}{*}{ Gene } & SNP & \multicolumn{5}{|c|}{ Favorable outcome } & \multicolumn{5}{|c|}{ Unfavorable outcome } & \multirow{2}{*}{$\begin{array}{l}\text { Risk allele } \\
\text { or genotype }\end{array}$} & \multirow{2}{*}{$\begin{array}{c}\text { OR } \\
(95 \% \mathrm{Cl})\end{array}$} & \multirow[t]{2}{*}{$P$} \\
\hline & ID & A & B & $A A$ & $A B$ & BB & A & B & AA & $A B$ & BB & & & \\
\hline C3 & rs1047286 & 543 & 111 & 218 & 107 & 2 & 169 & 37 & 69 & 31 & 3 & BB & $4.88(0.80-29.6)$ & 0.092 \\
\hline C3 & rs2230199 & 539 & 115 & 218 & 103 & 6 & 171 & 33 & 73 & 25 & 4 & BB & $2.18(0.60-7.90)$ & 0.223 \\
\hline C5 & rs17611 & 292 & 366 & 65 & 162 & 102 & 77 & 131 & 18 & 41 & 45 & BB & $1.70(1.08-2.67)$ & 0.021 \\
\hline C6 & rs1801033 & 422 & 232 & 140 & 142 & 45 & 137 & 67 & 45 & 47 & 10 & $A$ & $1.47(0.71-3.03)$ & 0.297 \\
\hline$C 7$ & rs1063499 & 257 & 401 & 57 & 143 & 129 & 90 & 114 & 23 & 44 & 35 & AA & $1.39(0.81-2.40)$ & 0.236 \\
\hline C7 & rs13157656 & 174 & 472 & 12 & 150 & 161 & 49 & 151 & 5 & 39 & 56 & BB & $1.28(0.82-2.01)$ & 0.282 \\
\hline C7 & rs60714178 & 91 & 565 & 8 & 75 & 245 & 34 & 176 & 5 & 24 & 76 & AA & $2.00(0.64-6.25)$ & 0.225 \\
\hline$C 8 B^{A}$ & rs12067507 & 35 & 621 & 8 & 19 & 301 & 21 & 185 & 7 & 7 & 89 & AA & $2.92(1.03-8.26)$ & 0.035 \\
\hline$C 8 B$ & rs12085435 & 624 & 28 & 298 & 28 & 0 & 185 & 17 & 86 & 13 & 2 & BB & $1.02(0.99-1.05)$ & 0.056 \\
\hline C9 & rs700233 & 386 & 250 & 114 & 158 & 46 & 110 & 78 & 32 & 46 & 16 & BB & $1.21(0.65-2.26)$ & 0.543 \\
\hline C9 & rs34882957 & 607 & 49 & 281 & 45 & 2 & 192 & 10 & 91 & 10 & 0 & $\mathrm{AA}$ & $1.52(0.74-3.13)$ & 0.252 \\
\hline $\mathrm{CFH}$ & rs505102 & 456 & 198 & 161 & 134 & 32 & 145 & 59 & 52 & 41 & 9 & $A$ & $1.12(0.52-2.43)$ & 0.773 \\
\hline CFH & rs1065489 & 107 & 549 & 16 & 75 & 237 & 38 & 168 & 6 & 26 & 71 & $A$ & $1.17(0.72-1.90)$ & 0.515 \\
\hline $\mathrm{CFH}$ & rs1410996 & 350 & 308 & 92 & 166 & 71 & 111 & 95 & 31 & 49 & 23 & AA & $1.11(0.68-1.80)$ & 0.675 \\
\hline $\mathrm{CFH}$ & rs3753396 & 100 & 558 & 8 & 84 & 237 & 32 & 174 & 2 & 28 & 73 & B & $1.26(0.26-6.02)$ & 0.560 \\
\hline CFH & rs6677604 & 513 & 143 & 197 & 119 & 12 & 163 & 43 & 64 & 35 & 4 & $\mathrm{AA}$ & $1.09(0.69-1.72)$ & 0.707 \\
\hline $\mathrm{CFH}$ & rs3753394 & 155 & 503 & 20 & 115 & 194 & 64 & 142 & 13 & 38 & 52 & AA & $2.23(1.07-4.65)$ & 0.029 \\
\hline $\mathrm{CFH}$ & rs1061170 & 434 & 224 & 148 & 138 & 43 & 137 & 73 & 50 & 37 & 18 & $\mathrm{BB}$ & $1.38(0.76-2.51)$ & 0.296 \\
\hline
\end{tabular}

For favorable and unfavorable outcome, the number of patients in each allele or genotype is listed. ${ }^{\mathrm{A} C o n t r o l}$ population did not comply with HWE.

younger and presented with less severe disease than patients for whom DNA was not obtained (Supplemental Table 2).

Genetic association study on common variants in the complement system. We selected all SNPs with a minor allele frequency of more than $5 \%$ in genes coding for complement components (C1QA, C1QB, C1QC, C2, C3, C5, C6, C7, C8B, C9, CFD, CFH, CFI, and CFP) for which a commercial genotyping assay was available. A total of 17 SNPs were genotyped using TaqMan SNP Genotyping Assays (Applied Biosystems). The genotyping success rate was more than $95 \%$ for all assays. In 16 out of 17 assays, genotype frequency of controls of mixed European descent concurred with the Hardy-Weinberg equilibrium (HWE; Supplemental Table 3). We compared the genotype frequency of patients with a favorable outcome, defined as a GOS score of 5 , indicating mild or no disability, with that of patients with an unfavorable outcome. Using a Bonferroni correction for multiple testing, we identified rs17611 in complement component 5 (C5; GG genotype) to be associated with unfavorable outcome in patients of mixed European descent with pneumococcal meningitis $(\mathrm{OR}, 2.25$; $95 \% \mathrm{CI}, 1.33-3.81 ; P=0.002)$. In a multivariate regression analysis, including previously identified important risk factors for unfavorable outcome (age, CSF wbc count $<1,000 / \mathrm{mm}^{3}$, score on the Glasgow Coma Scale, blood thrombocyte count, immunocompromise, otitis media, and/or sinusitis) (3), the predictive effect of rs17611 remained robust (OR, 1.92; 95\% CI, 1.09-3.26; $P=0.032$; Supplemental Table 4). Other SNPs frequencies were similar in patients with unfavorable and favorable outcome (Tables 2 and 3).

Complement in CSF of adults with bacterial meningitis. C5-convertase cleaves C5 into the anaphylatoxin C5a and fragment C5b. When $\mathrm{C} 5 \mathrm{~b}$ associates with $\mathrm{C} 6$ and $\mathrm{C} 7$, the complex becomes inserted into bacterial membranes and interacts with $\mathrm{C} 8$, permitting the binding of several copies of $\mathrm{C} 9$ to form the MAC (12). To explore the role of $\mathrm{C} 5$ in patients with bacterial meningitis, we measured CSF levels of C5a and terminal complement complex (TCC; sC5b-9) in the CSF of 204 out of 642 episodes, using the Quidel Microvue C5a and sC5b-9 ELISA Kits. Baseline characteristics and outcome were similar for patients with CSF available as compared with those of patients without CSF available. C5a and TCC levels were correlated with Glasgow Coma Scale scores on admission, death, and unfavorable outcome (Figure 1). Higher levels of C5a and TCC predicted increased parameters of CSF inflammation. There was no significant association between CSF C5a or TCC levels and rs17611 genotypes (C5a, $8.7 \mathrm{ng} / \mathrm{ml}$ [interquartile range, IQR, 2.0-43] in rs $17611 \mathrm{~A}$ vs. $16 \mathrm{ng} / \mathrm{ml}$ [IQR, 4.0-64] in rs17611GG, $P=0.29$; TCC, $2.0 \mu \mathrm{g} / \mathrm{ml}$ [IQR, 0.3-4.4] in rs17611A vs. $2.3 \mu \mathrm{g} / \mathrm{ml}$ [IQR, 0.5-5.5] in rs17611GG, $P=0.50)$. Patients with pneumococcal meningitis with the rs17611 GG genotype had lower CSF wbc counts $(2,185$ per $\mathrm{mm}^{3}$ [IQR, 375-7,738] vs. 3,956 per $\mathrm{mm}^{3}$ [IQR, 998-9,365]; $P=0.036$ ) but similar CSF protein and CSF glucose levels, as compared with those of patients with AA or AG alleles. Lower CSF wbc counts have been reported to predict unfavorable outcome in patients with community-acquired bacterial meningitis $(3,24)$. To obtain insight into the functional role of terminal complement components in bacterial meningitis, we next performed experiments using a mouse model of pneumococcal meningitis (25).

Expression profile of $\mathrm{C} 5 \mathrm{a}$ and the TCC C5b-9 in the mouse model of pneumococcal meningitis. To confirm that C5a and the TCC are expressed in the meningitis mouse model, we examined mouse brain homogenates from WT mice infected with $S$. pneumoniae. At 24 and 48 hours after infection, C5a and TCC levels were increased (Figure 2, A and B). Immunohistochemical staining was positive for $\mathrm{C} 5 \mathrm{a}$ and TCC in and around inflammatory infiltrates in brains of infected mice (Figure 2, C and D). TCC expression was also detected in cortical vessels (Figure 2D).

Functional analysis of C5a, MAC, and C3 in the mouse model of pneumococcal meningitis. Next, we examined the functional role of the anaphylatoxins, C5a and C3a, and MAC in our mouse model using 


\section{Table 3}

Genotyping analysis of 17 common complement component polymorphisms in 217 patients of mixed European descent with pneumococcal meningitis with favorable outcome and 83 with unfavorable outcome

\begin{tabular}{|c|c|c|c|c|c|c|c|c|c|c|c|c|c|c|}
\hline \multirow[t]{2}{*}{ Gene } & \multirow{2}{*}{$\begin{array}{l}\text { SNP } \\
\text { ID }\end{array}$} & \multicolumn{5}{|c|}{ Favorable outcome } & \multicolumn{5}{|c|}{ Unfavorable outcome } & \multirow{2}{*}{$\begin{array}{l}\text { Risk allele } \\
\text { or genotype }\end{array}$} & \multirow{2}{*}{$\begin{array}{c}\text { OR } \\
(95 \% \mathrm{CI})\end{array}$} & \multirow[t]{2}{*}{$P$} \\
\hline & & A & B & $A A$ & $A B$ & BB & A & B & $A A$ & $A B$ & BB & & & \\
\hline C3 & rs1047286 & 354 & 76 & 141 & 72 & 2 & 127 & 33 & 50 & 27 & 3 & BB & $4.15(0.68-25.3)$ & 0.125 \\
\hline C3 & rs2230199 & 348 & 82 & 138 & 72 & 5 & 129 & 29 & 54 & 21 & 4 & BB & $2.24(0.59-8.56)$ & 0.227 \\
\hline C5 & rs17611 & 197 & 235 & 43 & 111 & 62 & 57 & 107 & 14 & 29 & 39 & BB & $2.25(1.33-3.81)$ & 0.002 \\
\hline C6 & rs1801033 & 276 & 154 & 90 & 96 & 29 & 107 & 51 & 36 & 35 & 8 & $A$ & $1.40(0.61-3.19)$ & 0.429 \\
\hline C7 & rs1063499 & 174 & 258 & 38 & 98 & 80 & 72 & 86 & 20 & 32 & 27 & $\mathrm{AA}$ & $1.57(0.85-2.91)$ & 0.149 \\
\hline C7 & rs13157656 & 115 & 305 & 6 & 103 & 101 & 41 & 117 & 5 & 31 & 43 & BB & $1.30(0.77-2.19)$ & 0.320 \\
\hline$C 7$ & rs60714178 & 59 & 373 & 6 & 47 & 163 & 28 & 136 & 5 & 18 & 59 & $\mathrm{AA}$ & $2.25(0.67-7.58)$ & 0.179 \\
\hline$C 8 B^{A}$ & rs12067507 & 26 & 404 & 7 & 12 & 196 & 14 & 146 & 5 & 4 & 71 & $\mathrm{AA}$ & $1.96(0.61-6.37)$ & 0.253 \\
\hline$C 8 B$ & rs12085435 & 402 & 20 & 191 & 20 & 0 & 144 & 12 & 68 & 8 & 2 & BB & $1.03(0.99-1.06)$ & 0.073 \\
\hline C9 & rs700233 & 254 & 160 & 73 & 108 & 26 & 87 & 57 & 25 & 37 & 10 & $\mathrm{BB}$ & $1.11(0.51-2.43$ & 0.792 \\
\hline c9 & rs34882957 & 403 & 27 & 189 & 25 & 1 & 151 & 7 & 72 & 7 & 0 & AA & $1.43(0.59-3.44)$ & 0.425 \\
\hline CFH & rs505102 & 291 & 137 & 100 & 91 & 23 & 109 & 49 & 37 & 35 & 7 & $A$ & $1.08(0.46-2.52)$ & 0.862 \\
\hline CFH & rs1065489 & 68 & 362 & 10 & 48 & 157 & 30 & 130 & 4 & 22 & 54 & $A$ & $1.26(0.72-2.19)$ & 0.417 \\
\hline $\mathrm{CFH}$ & rs1410996 & 231 & 201 & 60 & 111 & 45 & 85 & 75 & 24 & 37 & 19 & $\mathrm{AA}$ & $1.10(0.63-1.93)$ & 0.735 \\
\hline CFH & rs3753396 & 64 & 368 & 5 & 54 & 157 & 25 & 135 & 1 & 23 & 56 & $B$ & $1.89(0.22-16.40)$ & 0.482 \\
\hline CFH & rs6677604 & 343 & 87 & 134 & 75 & 6 & 129 & 31 & 52 & 25 & 3 & $\mathrm{AA}$ & $1.14(0.67-1.94)$ & 0.641 \\
\hline $\mathrm{CFH}$ & rs3753394 & 92 & 340 & 10 & 72 & 134 & 47 & 113 & 7 & 33 & 40 & $\mathrm{AA}$ & $1.96(0.72-5.32)$ & 0.182 \\
\hline $\mathrm{CFH}$ & rs1061170 & 278 & 154 & 95 & 88 & 33 & 108 & 56 & 39 & 30 & 13 & $\mathrm{BB}$ & $1.04(0.52-2.08)$ & 0.922 \\
\hline
\end{tabular}

For favorable and unfavorable outcome, the number of patients in each allele or genotype is listed. ${ }^{A}$ Control population did not comply with HWE.

different mutants. Components of the complement system are known to modulate inflammatory responses $(12,26)$.

First, we compared mice with a deficiency of the C5a receptor (C5ar1 $1^{-/-}$mice) to WT mice. CSF wbc count in infected $\mathrm{C} 5 \mathrm{arl}^{-/-}$ mice was decreased to $25 \%$ of that in WT mice (Figure 3 ). The reduced inflammatory response in $\mathrm{C} \mathrm{arl}^{-/-}$mice was associated with better clinical status (clinical score shown in Figure 3), with less severe hypothermia, reduced weight loss, and conserved exploratory behavior in the open-field test (OFT) $\left(\mathrm{C}^{\circ} \mathrm{ar} 1^{-1-}\right.$ vs. WT, body temperature, $37.3^{\circ} \mathrm{C} \pm 0.42^{\circ} \mathrm{C}$ vs. $36.6^{\circ} \mathrm{C} \pm 0.54^{\circ} \mathrm{C}, P=0.004$; weight loss, $11.1 \% \pm 1.58 \%$ vs. $13.3 \% \pm 2.38 \%, P=0.031$; OFT, $23 \pm 22$ fields vs. $3 \pm 4$ fields, $P=0.019$ ).

A strong granulocytic inflammatory response contributes substantially to neuropathology in pneumococcal meningitis (27); this was supported by our finding that granulocyte depletion was protective against meningitis-related brain damage (Supplemental Figure 1). Therefore, we evaluated major meningitis-associated intracranial complications in our model: raised intracranial pressure (ICP), decreased blood-brain barrier (BBB) integrity, and intracerebral hemorrhages. BBB breakdown (brain albumin content) was combined with the number of intracerebral hemorrhages to obtain the neuroscore, as described previously (25). $\mathrm{C} \mathrm{arl}^{-1-}$ mice had reduced ICP and lower neuroscores when compared with those of WT mice (Figure 3 ). There was no difference in cerebellar bacterial titers $\left(6.58 \pm 0.59 \log ^{10} \mathrm{CFUs} /\right.$ cerebellum in WT mice vs. $6.15 \pm 0.73 \log ^{10} \mathrm{CFU} /$ cerebellum in $\mathrm{C} \mathrm{ar} 1^{-/-}$mice) or mortality rate ( 0 out of 10 vs. 0 out of 9 for WT vs. $C 5$ ar $1^{-1-}$ mice) between $\mathrm{C}_{5} \mathrm{arl}^{-/-}$and WT mice. The altered recruitment of CSF inflammatory cells in $\mathrm{C} \mathrm{ar} \mathrm{1}^{-/-}$mice prompted us to analyze the levels of cytokines and inflammatory mediators in mouse brain homogenates. Amounts of IL-6 (data not shown), CXCL1/KC, and CXCL2/MIP-2 were all reduced in infected $\mathrm{C} \mathrm{ar} 1^{-/}$mice compared with those in infected WT mice (Figure 3).
In order to evaluate whether the decreased CSF wbc count observed in the $\mathrm{C}_{5} \mathrm{arl}^{-/-}$mice was mediated through chemokine regulation by $\mathrm{C} 5 \mathrm{a}$, infected animals were treated with anti-CXCL2/ MIP-2 antibodies, either alone or in combination with anti-CXCL1/ KC antibodies. Treatment with anti-CXCL2/MIP-2 antibodies alone reduced CSF wbc count by $40 \%$ (not significant), whereas, when combined with anti-CXCL1, treatment caused a reduction of CSF wbc count by $63 \%(P=0.003)$. The animals treated with both CXCL1 and CXCL2 antibodies were in a better clinical state compared with that of the untreated mice (Supplemental Table 5).

To analyze the role of the MAC, we investigated mice with a mutation in the complement component 6 gene (C6-1- mice), which are unable to form the MAC, and mice gene deleted for $\mathrm{CD} 59$ (Cd59 $\mathrm{a}^{-/-}$mice), the in vivo inhibitor of the MAC (12). $\mathrm{C6}^{-/-}$ mice with pneumococcal meningitis tended to have lower CSF wbc counts as compared with those of WT mice (Supplemental Figure 2), whereas $C d 59 a^{-/-}$mice had increased CSF wbc counts compared with those of WT animals (Supplemental Figure 3). No

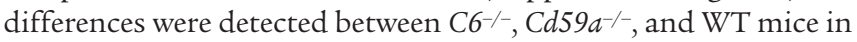
clinical scores, ICP, or neuroscores (Supplemental Figure 3). However, the mortality rate among $\mathrm{C6}^{-/-}$mice was higher (7 out of 14

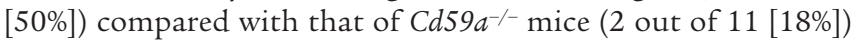
and WT mice (2 out of 20 [10\%]). This difference was attributable to a more severe damage of the BBB in $\mathrm{C6}^{-/-}$mice compared with that of WT mice (brain albumin content, $487.0 \pm 287.7 \mathrm{ng} / \mu \mathrm{g}$ vs. $242.7 \pm 178.0 \mathrm{ng} / \mu \mathrm{g}, P=0.014)$. Levels of IL- 6 and CXCL2/MIP-2 were similar among the 3 mouse strains.

We next investigated the role of $\mathrm{C} 3 \mathrm{a}$ in pneumococcal meningitis. The anaphylatoxin $\mathrm{C} 3 \mathrm{a}$ has been shown to be involved in immune regulation of inflammatory CNS diseases (28), and we previously described increased expression of the C3a receptor in mice with pneumococcal meningitis (21). Mice deficient in the $\mathrm{C} 3 \mathrm{a}$ receptor ( $\mathrm{C}_{\mathrm{arl}} \mathrm{I}^{-/}$mice) and mice expressing $\mathrm{C} 3 \mathrm{a}$ exclusively 

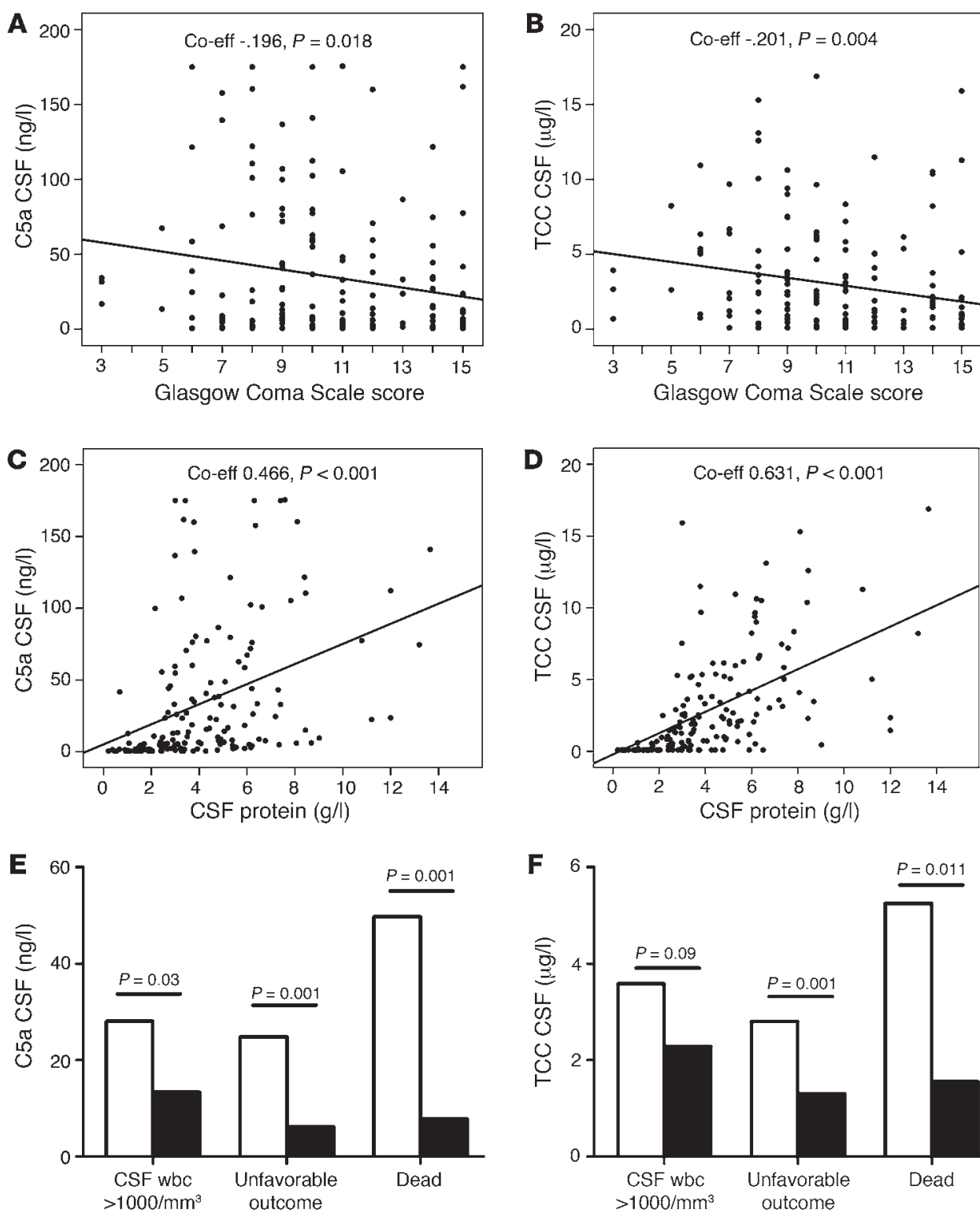
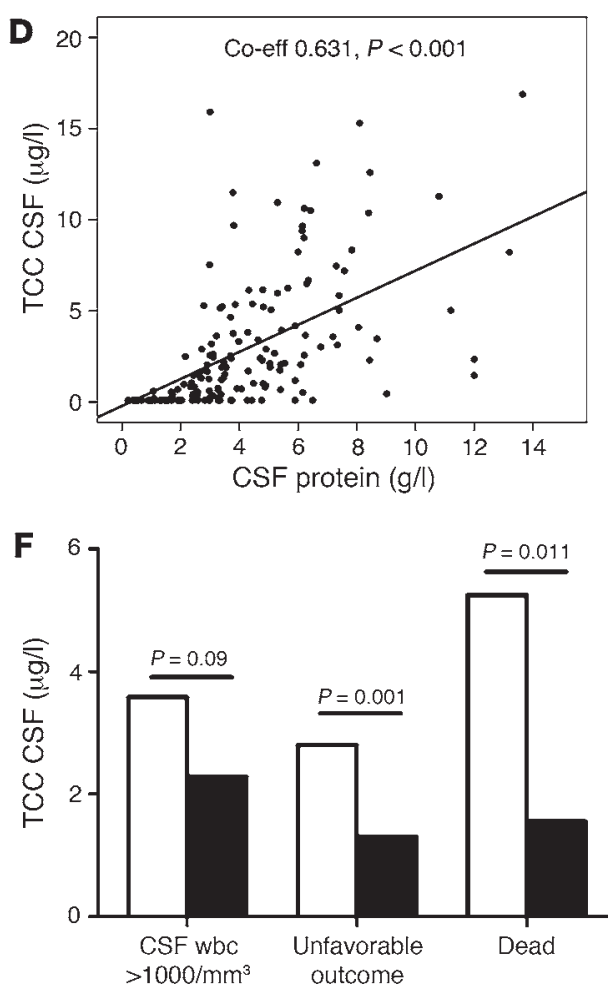

Figure 1

Association of $\mathrm{C} 5 \mathrm{a}$ and $\mathrm{TCC}$ concentrations in CSF with disease severity and outcome. (A-D) Pearson correlation analysis of $\mathrm{C} 5 \mathrm{a}(\mathbf{A}$ and $\mathbf{C})$ and TCC (B and $\mathbf{D}$ ) CSF levels with Glasgow Coma Scale score and CSF protein concentration. Each dot represents an individual patient; diagonal lines represent the mean. Co-eff, coefficient. (E and F) Median (E) C5a and (F) TCC CSF levels in patients with CSF wbc counts of more than 1,000 (white bars) versus those with less than 1,000 (black bars), unfavorable (white bars) versus favorable outcome (black bars), and deceased (white bars) versus surviving patients (black bars). $P$ values for differences between groups were determined with the Mann-Whitney U test. in the CNS using the GFAP promoter (C3a/GFAP mice) were compared with infected WT mice. C3a/GFAP mice had increased CSF wbc counts as compared with those of WT and $\mathrm{C}$ ar $1^{-1-}$ mice (Supplemental Figure 3), but other parameters were similar (clinical scores, ICP, neuroscores, proinflammatory mediators, and cytokines; Supplemental Figure 3).

Adjuvant treatment with C5 antibody. The experiments performed with ${\mathrm{C} 5 \mathrm{ar} 1^{-1-}}^{-}$mice suggested a major role for $\mathrm{C} 5 \mathrm{a}$ in the regulation of the immune response in pneumococcal meningitis; we therefore evaluated treatment with a neutralizing monoclonal antibody directed against murine C5 (C5-Ab, BB5.1) in the model. Animals were given i.p. C5-Ab or i.p. IgG (1 mg per mouse, each) prior to infection. Levels of cerebral sC5b-9 were significantly reduced in animals treated with $\mathrm{C} 5-\mathrm{Ab}$ (Figure 4). Consistent with that in $\mathrm{C}^{\mathrm{ar} 1^{-/-}}$mice, WT mice treated with $\mathrm{C} 5-\mathrm{Ab}$ prior to infection displayed a reduced CSF wbc count accompanied by better clinical scores when compared with those of animals treated with mouse IgG (Figure 4).
To define the site of action of C5 neutralization, we applied a low dose of $\mathrm{C} 5-\mathrm{Ab}(30 \mu \mathrm{g}$ per mouse) to infected mice either by the i.p. (systemic) or intrathecal (i.t.) (local) route. Mice treated i.t. with $\mathrm{C} 5$-Ab had lower CSF leukocyte counts, less meningitis-associated intracranial complication, and better clinical status, as compared with mice treated with control IgG (Supplemental Table 5). No difference between infected mice treated with i.p. C5-Ab or control IgG was observed.

We next compared adjunctive $\mathrm{C} 5-\mathrm{Ab}$ treatment with adjunctive treatment with dexamethasone, the standard adjunct in humans with pneumococcal meningitis, $(1,8)$, or adjunctive treatment with neutralizing TLR 2 and TLR 4 antibodies. Treatment with TLR 2 and TLR 4 antibodies was based on our recent observation that TLR2 and TLR4 are essential in mounting the CNS innate immune response in pneumococcal meningitis (29). All adjunctive therapies were administered i.p. 24 hours after infection concomitant with antibiotic treatment consisting of ceftriaxone. In these experiments, i.p. treatment with PBS or IgG served as control. 

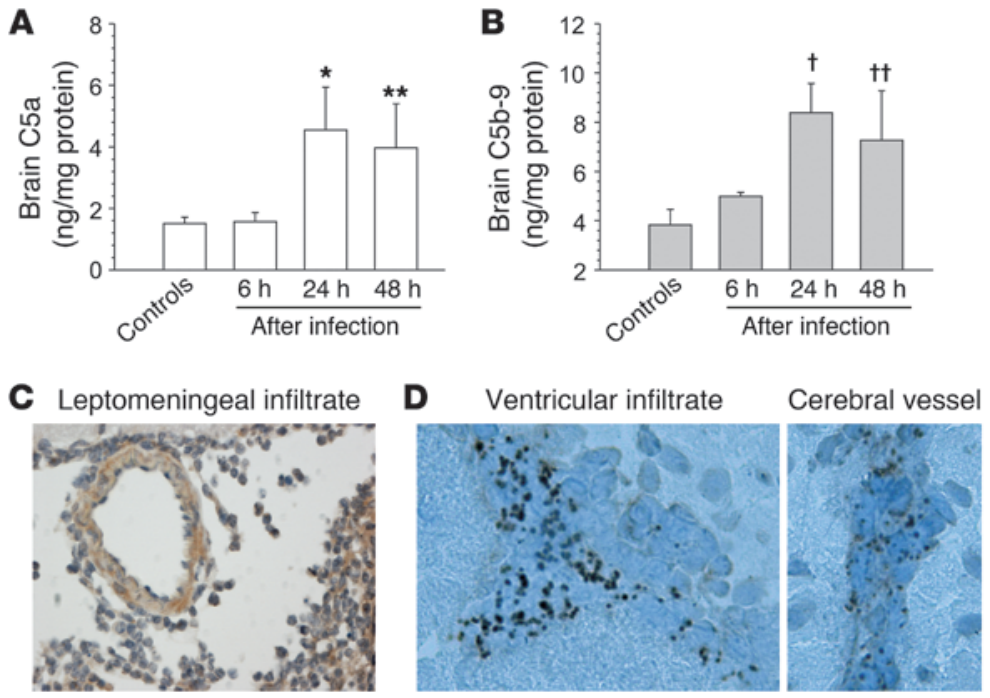

\section{Figure 2}

Expression profile of the anaphylatoxin $\mathrm{C5a}$ and the TCC in mice with pneumococcal meningitis. (A) Levels of C5a $(\mathrm{ng} / \mathrm{mg})$ and (B) TCC $(\mathrm{ng} / \mathrm{mg})$ were determined by ELISA in brain homogenates of WT mice intracisternally injected with PBS (controls, $n=4$ ) or infected with $S$. pneumoniae at different time points after infection (6, 24, and 48 hours; $n=5$ each) (above). Levels of C5a and TCC were both found to be increased at 24 hours $\left({ }^{*} P=0.006\right.$ and $\left.{ }^{\dagger} P=0.002\right)$ and 48 hours ( ${ }^{* \star} P=0.014$ and ${ }^{t+} P=0.016$ ) after infection (unpaired Student's test and Bonferroni correction for multiple measurements; data are shown as mean $\pm \mathrm{SD}$ ). (C and D) Formalin-fixed and paraffin-embedded brains of WT mice infected for 24 hours were used for immunohistochemistry. C5a and TCC immunoreactivity was visualized with streptavidin horseradish peroxidase and $\mathrm{DAB}$, which yields a brown reaction product. In infected mice, positive immunostaining was seen in the inflammatory infiltrates for both C5a (original magnification, $\times 400[\mathbf{C}])$ and TCC (original magnification, $\times 1,000[\mathrm{D}]$ ).

Treatment with the C5-Ab prevented lethal outcome in all treated animals, as shown by a significant decrease in the mortality rate as compared with treatment with IgG (deaths, 7 out of 21 mice [33\%]; Figure 5A). Adjunctive treatment with dexamethasone reduced the mortality rate as compared with that with PBS (deaths, 2 out of 10 mice [20\%] vs. 5 out of 16 mice [31\%]) but was less effective when compared with treatment with C5-Ab (Figure 5C). Adjunctive treatment with anti-TLR2 and TLR4 antibodies caused a significant attenuation of meningeal inflammation and brain tissue damage, in line with our previous study (29) (Supplemental Table 5); however, these antibodies had no effect on mortality (deaths, 2 out of 8 mice [25\%]; Figure 5B). Adjunctive treatment with C5-Ab, but not with dexamethasone or anti-TLR2 and 4 antibodies, resulted in a reduction of meningitis-induced brain damage (neuroscores, $2.3 \pm 1.6$ vs. $4.2 \pm 1.6$ in IgG-treated mice [ $P=0.012]$, vs. $4.3 \pm 1.5$ in anti-TLR2 - and TLR4-treated mice, $3.5 \pm 2.0$ in dexamethasonetreated mice, and $3.7 \pm 1.7$ in PBS-treated mice).

\section{Discussion}

We demonstrated that a common variant in C5 was associated with unfavorable outcome in adults with community-acquired pneumococcal meningitis. The anaphylatoxin C5a was identified as the crucial complement product in pneumococcal meningitis. Neutralization experiments showed that adjunctive treatment with C5-Ab improved outcome in mice with pneumococcal menin- gitis. The observed effect of C5-Ab was superior to that of adjuvant dexamethasone, the antiinflammatory drug that is currently recommended in clinical guidelines $(2,30)$. Since anti-C5 antibodies are currently licensed for clinical use (eculizumab) or used in clinical trials (pexelizumab) $(31,32)$, our results present a promising treatment option for future patients with communityacquired bacterial meningitis.

Patients with the rs 17611 GG genotype were at higher risk for unfavorable outcome as compared with carriers of the A allele (OR, 2.26; 95\% CI, 1.30-3.94). Our genetic association study was nationwide, and, therefore, we were able to study a representative sample of adults with acute bacterial meningitis. The prospective approach allowed us to collect comprehensive clinical data, resulting in a well-defined group of patients with microbiologically confirmed community-acquired bacterial meningitis. Our large sample gave us the statistical power to perform a Bonferroni correction for multiple testing, and, subsequently, we were able to validate our findings in a mouse model of pneumococcal meningitis.

Patients with the rs17611 risk genotype GG had lower CSF wbc counts on admission. Clinical studies have shown that lower CSF wbc counts on admission in patients with bacterial meningitis are associated with sepsis and systemic compromise and adverse outcomes later in disease course $(3,33)$. Sepsis was not more common in patients with the GG genotype in this study, although power may be insufficient to detect such a difference. Animals studies in a pneumococcal meningitis model showed that lower CSF wbc counts early in disease course were associated with high bacterial load, which correlates with intracranial complications and poor outcome (34). These experiments also showed that later in disease course, higher CSF wbc counts correlated with high bacterial loads and were associated with poor outcome (34). Other experimental work in pneumococcal meningitis showed a critical role for the cumulative exposure to bacteria during the infection period (35). We speculate that the lower CSF wbc counts in patients with the risk genotype may be due to a reduced chemoattractant function of C5a.

Functional studies have previously shown that SNPs in complement factors can influence complement activation and binding affinity independent of concentration $(36,37)$. A study on rs17611 function showed the GG genotype was associated with reduced serum C5 concentration among 100 healthy volunteers (38). A follow-up study, however, showed that these subjects had serum C5 activity similar to that of those with rs17611 AA/AG, despite lower C5 serum concentration (39). This observation is consistent with our results, which showed similar C5a and TCC concentration in both genotypes.

The anaphylatoxin C5a is a powerful chemoattractant, guiding neutrophils but also directly stimulating the production of cytokines, chemokines, and adhesion molecules (12, 40). Major neurologic complications in patients with pneumococcal meningitis include cerebrovascular complications and brain edema, which are caused, at least partly, by massive neutrophilic inflammatory reaction. In patients with bacterial meningitis, CSF C5a concentrations were markedly elevated, and C5a levels were associated with high CSF wbc counts and unfavorable outcome. In our 

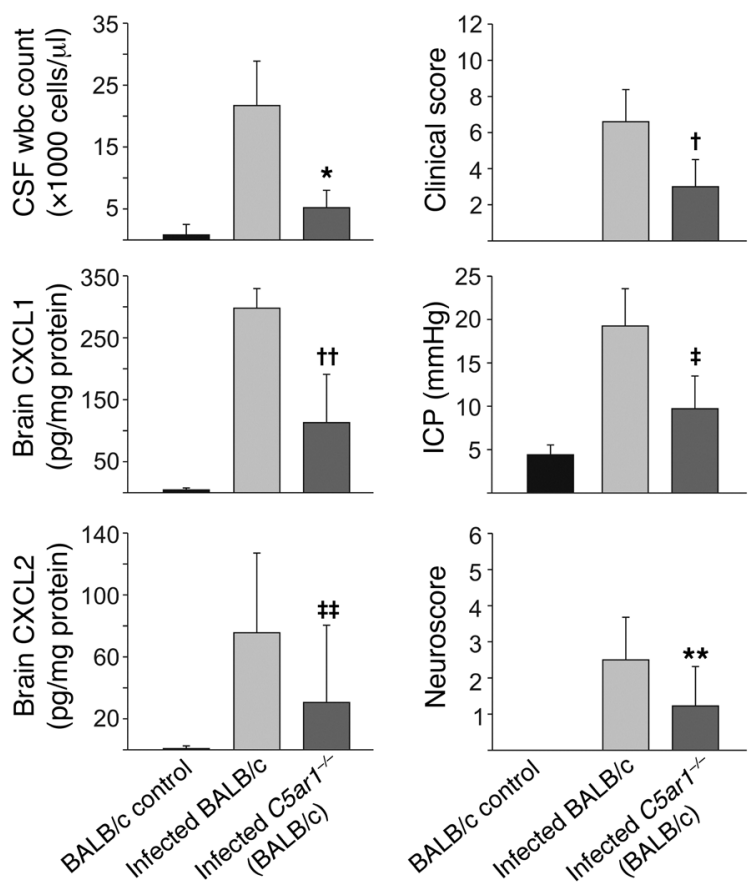

mouse model, deficiency of the receptor for C5a led to an improved clinical status and clinical course. C5a receptor deficiency and C5 neutralization resulted in a marked reduction of CSF wbc counts in the pneumococcal mouse model, with lower concentrations of IL-6, CXCL1, and CXCL2 in C5 $\mathrm{rr}^{-/-}$mice. Pretreatment with CXCL1 and CXCL2 antibodies caused a reduction of CSF wbc count, but to a lesser extent than that found in $\mathrm{C} \mathrm{arl}^{-/-}$mice, indicating that $\mathrm{C} 5$ a regulates chemokine expression but also has a direct chemotactic effect. In our experiments, i.t. anti-C5 treatment also led to a significant reduction in CSF pleocytosis. Previous work showed that treatment with antibodies to native human C5 inhibited leukocyte influx in rabbits with pneumococcal meningitis (40), and intracisternal administration of C5a caused rapid influx of wbc into the CSF of rabbits (41). C5a-mediated neutrophilic inflammation may cause direct tissue injury by release of cytotoxic products from neutrophils and/or by precipitating cerebral vasculitis and a subsequent reduction in blood supply to the brain (27). This concept is supported by evidence presented here and in previous studies demonstrating that neutrophil depletion approaches are beneficial in pneumococcal meningitis, particularly when used as adjunctive treatment with antibiotic therapy $(27,42)$. These data seem to contradict our observation in humans that the rs17611 risk genotype GG had lower CSF wbc count; however, CSF wbc counts were determined in samples withdrawn on admission, early in the course of the disease. Bacterial titers were not determined in our patients; nevertheless, it is noteworthy that the inoculum size does not correlate with

\section{Figure 3}

Role of $\mathrm{C} 5 \mathrm{a}$ in the mouse model of pneumococcal meningitis. To evaluate the role of $\mathrm{C} 5 \mathrm{a}$, C5ar1 $1^{-1-}$ mice $(n=9)$ were examined. Animals were infected with $S$. pneumoniae and evaluated at 24 hours after infection for CSF leukocyte count (CSF wbc count), clinical score, ICP, BBB breaching and intracerebral hemorrhage combined in the neuroscore, and expression of proinflammatory mediators and cytokines, namely CXCL1/KC and CXCL2/MIP-2. Infected C5ar1-/- mice were compared with infected WT mice (BALB/c, male; $n=10$ ). BALB/c mice intracisternally injected with PBS served as controls (BALB/c controls; $n=6)$. Compared with infected WT mice, C5ar1-1- mice displayed reduced CSF leukocytosis ( $\left.{ }^{*} P=0.001\right)$ accompanied by a better clinical status $\left({ }^{\dagger} P=0.001\right)$ and reduced secondary CNS complications (reduced ICP $\left[{ }^{\ddagger} P=0.001\right]$ and neuroscore $\left[{ }^{\star \star} P=0.025\right]$ ). Levels of IL-6, CXCL1, and CXCL2 were reduced in C5ar1 $1^{-1}$ mice $(P=0.038$, ${ }^{\dagger \dagger} P=0.019$, and $\ddagger \ddagger P=0.047$, respectively; unpaired Student's test; data are shown as mean $\pm S D$ ).

subsequent bacterial titers but does determine the disease kinetics. As a consequence, the precise classification of disease stage is not possible in patients with pneumococcal meningitis.

The role of C5a is not limited to its chemoattractant and proinflammatory function. First, C5a can induce the expression of tissue factor and plasminogen activator inhibitor-1, leading to amplification of coagulation and inhibition of fibrinolysis (43, 44). The relation between $\mathrm{C} 5 \mathrm{a}$ and coagulation pathways is reciprocal: thrombin directly cleaves $\mathrm{C} 5$ and generates active $\mathrm{C} 5 \mathrm{a}$, and thrombin-activatable carboxypeptidase B inhibits C5a $(43,45)$. The procoagulant activity of $\mathrm{C} 5$ a may represent an additional and/or additive factor in the vascular occlusion process in bacterial meningitis $(24,46,47)$. Second, C5a increases vascular permeability, thereby contributing to meningitis-induced brain edema.
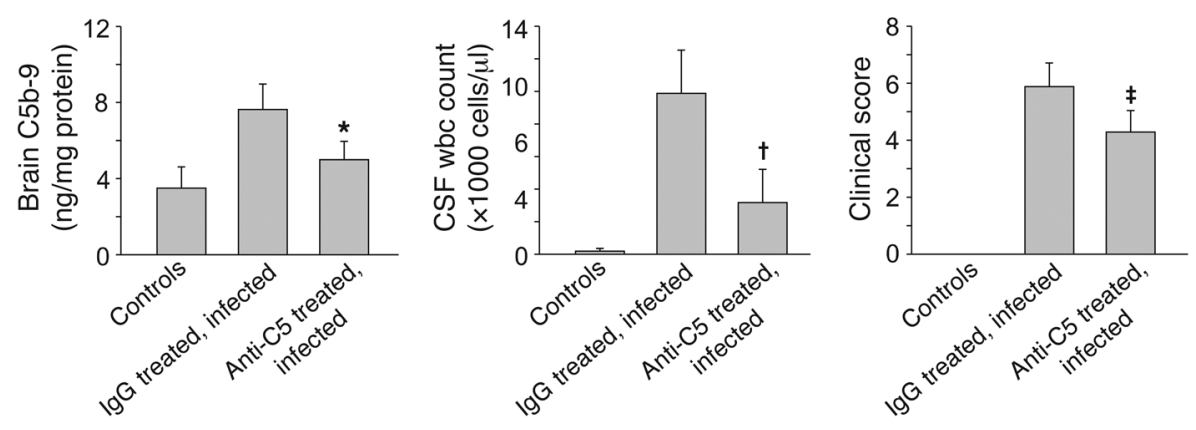

Figure 4

Pretreatment model of C5-Ab. To confirm the activity of C5-Ab, we first treated animals with i.p. C5-Ab $(n=7)$ or i.p. IgG $(n=12)$ prior to infection. After 24 hours, expression of the TCC C5b-9 was determined in mouse brain homogenates (left). Additionally, animals were evaluated for CSF leukocyte count (CSF wbc count; middle) and clinical score (right). Animals pretreated with the antibody to $C 5$ prior to infection displayed reduced levels of $C 5 b-9\left({ }^{\star} P=0.012\right)$ and reduced CSF leukocytosis $\left({ }^{\dagger} P=0.001\right)$ accompanied by a better clinical status $\left({ }^{\ddagger} P=0.002\right)$. Unpaired Student’s test; data are shown as mean \pm SD. 
A

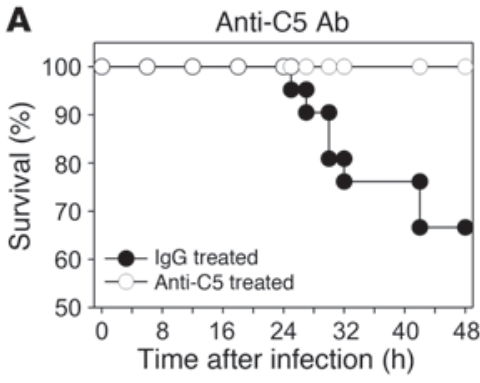

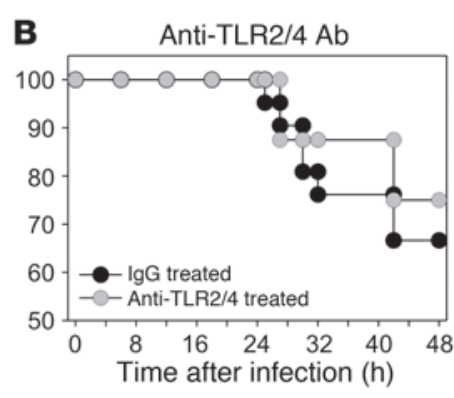

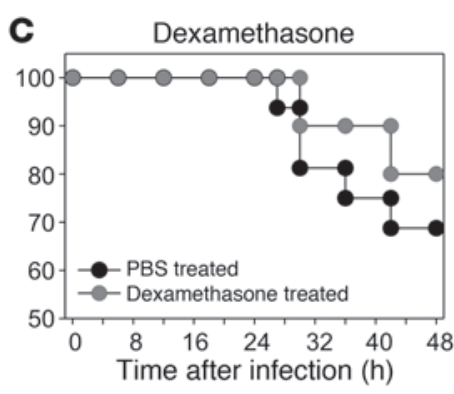

D

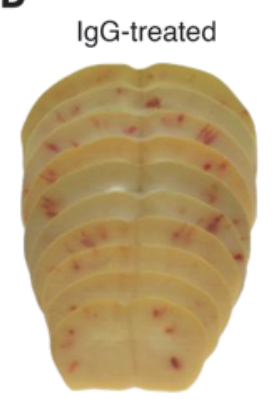

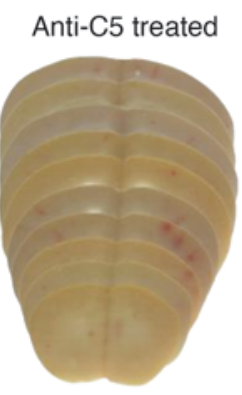
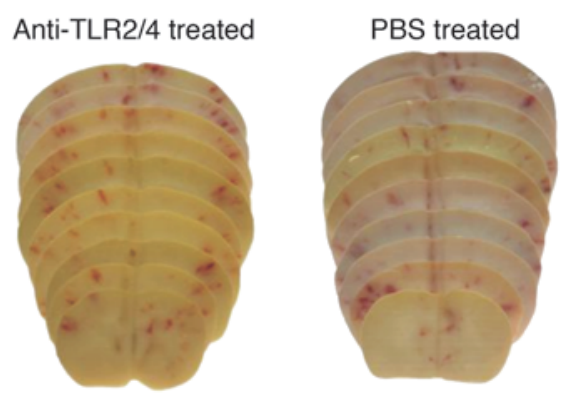

Dexamethasone treated

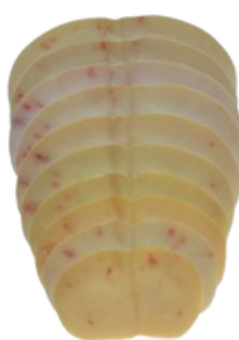

\section{Figure 5}

Effect of additional treatment with a monoclonal antibody to murine $\mathrm{C} 5$ or with dexamethasone on survival in mice with pneumococcal meningitis. Additional treatment with a monoclonal antibody to (A) murine C5 (anti-C5-Ab; $n=10$ ), (B) antibody to TLR2 and TLR4 (anti-TLR2/4; $n=8$ ), or $(\mathbf{C})$ dexamethasone $(n=10)$ was administered 24 hours after infection together with antibiotic treatment with ceftriaxone. Administration of an $\mathrm{IgG}_{1}$ isotype control $\left(\mathrm{IgG}_{1} ; n=21\right)$ or PBS $(n=16)$ served as control. Kaplan Meier curves of survival are shown. Additional treatment with $\mathrm{C} 5$-Ab prevented lethal outcome in all animals $(P=0.047)$. Adjuvant therapy with dexamethasone or with anti-TLR2 and TLR4 antibodies had no significant effect on meningitis-associated death (death rate, $20 \%$ or $25 \%$ compared with $31 \%$ in PBS-treated animals). (D) Representative brain sections obtained from mice from the different experimental groups 48 hours after infection. Only treatment with C5-Ab led to a visible reduction in cerebral hemorrhages observed in infected mice treated with either control lgG or the vehicle PBS.

In our experiments, C5a receptor deficiency and C5 neutralization resulted in a reduction of brain albumin concentrations, indicative of a protective effect against meningitis-induced BBB breakdown. In line with this finding is the recent observation that C5a receptor inhibition maintained the integrity of the BBB in experimental lupus (48). Moreover, silencing of the C5ar1 gene with siRNA was found to prevent the bacterial lipopolysaccharideinduced increased vascular permeability in multiple organs (49). Finally, very high concentrations of C5a were shown to induce rapid apoptosis in neuronal cells via neuronal C5a receptor-associated signal transduction pathways (50), whereas in lower concentrations, C5a inhibited apoptosis, induced neuroproliferation, and decreased glutamate excitotoxicity (51). These findings imply that C5a may function as a direct modulator of brain tissue injury in pneumococcal meningitis.

Adjunctive treatment with $\mathrm{C} 5$ - $\mathrm{Ab}$ resulted in a reduction in meningitis-induced brain damage and prevented death, despite having no effect on either bacterial outgrowth in the CSF and blood or antibiotic-induced bacterial killing in experimental pneumococcal meningitis. Complement-mediated opsonophagocytosis and not MAC-mediated bacterial lysis is the major host defense mechanism against invasive pneumococcal infections. In contrast, MAC is known to play a major role in meningococcal killing. AntiC5 antibodies that block C5a and MAC formation were found to interfere with bacterial lysis using a human whole blood model of meningococcal sepsis (52). However, this study also showed that C5a-specific antibodies (monoclonal antibody 137-126) can bind the C5a moiety and inhibit the harmful effects of C5a while preserving MAC-mediated bacterial killing (52).

The observed adjuvant effect of C5-Ab was superior to that of neutralizing antibodies against TLR2 and TLR4, 2 pattern recognition receptors (PRRs) that have been shown to be essential for mounting the innate immune response to pneumococcal infection of the CNS in experiments using Tlr2 ${ }^{-/-}, \mathrm{Tlr} 4^{-/-}$, and $\mathrm{Tlr} 2 / 4^{-/-}$mice $(27,29)$. Indeed, in our neutralization experiments, antibodies to both TLR2 and TLR4, when administered prior to infection, produced a similar phenotype to that seen in the receptor-deficient animals with reduced CSF pleocytosis and improved brain pathology. Our data show that TLR signaling is vital for the initial innate immune response but dispensable for the maintenance of inflammation in meningitis during the later disease course. The presence of $S$. pneumoniae in the subarachnoid space is initially recognized by TLR 2 and TLR 4 as well as other PRRs. Activation of TLR 2 and TLR4 by pneumococci leads to MyD88-dependent induction and activation of the complement system in the brain (29). Among the complement components produced, $\mathrm{C} 5$ and its activation product C5a have now been singled out to be crucial for the propagation of the inflammatory reaction. The C5a-driven inflammatory reaction, in turn, contributes substantially to meningitis-induced vascular and tissue injury, thus representing a major determinant for the outcome of the disease.

Our study has some limitations. A selection bias was introduced since DNA was not available for a considerable proportion of patients (32\%), particularly those with more severe disease. Inclu- 
sion of patients with less severe disease will decrease study power, resulting in type II errors. However, this will not negate the association of rs17611 with outcome. The nationwide design allowed us to detect this selection bias $(11,53)$. Furthermore, there may be functional differences between the complement systems of humans and mice. Animal models in rheumatoid arthritis showed a beneficial effect of C5a receptor blockage, but a clinical trial showed no benefit $(54,55)$. However, bacterial opsonization by mouse complement is known to be similar to the human situation (56). Therefore, we believe that our model is valid and provides valuable information on complement function in pneumococcal meningitis. Overall, we have used a clinical-based approach to generate a hypothesis that was subsequently confirmed in animal studies.

\section{Methods}

\section{Dutch bacterial meningitis cohort}

The nationwide prospective cohort study included patients with bacterial meningitis that were older than 16 years of age with positive CSF cultures, who were identified by NRLBM from March 2006 to June 2009. NRLBM provided the names of the hospitals in which patients with bacterial meningitis had been admitted 2-6 days previously, and the treating physician was contacted for permission to include the patient. Controls for exposure/ susceptibility were patients' partners or their nonrelated proxies living in the same dwelling. Data on age, sex, and ethnicity of controls were collected. Secured online case-record forms were used to collect data on patient history, symptoms and signs on admission, treatment, complications, and outcome. Outcome was graded at discharge according to the GOS, a wellvalidated instrument with good inter-observer agreement (23). A score of 1 on this scale indicates death; a score of 2 indicates a vegetative state; a score of 3 indicates severe disability; a score of 4 indicates moderate disability; and a score of 5 indicates mild or no disability. A favorable outcome was defined as a score of 5 , and an unfavorable outcome was defined as a score of 1 to 4 . Blood from patients and controls for DNA extraction was collected in sodium/EDTA. DNA was isolated with the Gentra Puregene Isolation Kit (Qiagen), and quality control procedures were performed to determine the yield and purity.

\section{Genotyping}

A total of 17 common SNPs in the complement system were genotyped using TaqMan SNP Genotyping Assays (Applied Biosystems) with $96 \times 96$ Dynamic Arrays (Fluidigm) by Service XS, Leiden, the Netherlands, and the Genetics Core Facility in the Academic Medical Center. Laboratory personnel were blinded to clinical information.

\section{CSF complement analysis}

CSF of patients was obtained from the diagnostic lumbar puncture. Subsequently, CSF and $\mathrm{wbc}$ were stored separately at $-80^{\circ} \mathrm{C}$. CSF complement component $\mathrm{C} 5 \mathrm{a}$ and TCC levels were determined using the Microvue C5a and sC5b-9 (TCC) Quidel ELISA Kits according to the manufacturer's instructions. Strength of relationships between C5a and TCC levels and clinical or biological features was assessed by Spearman's correlation tests.

\section{Animal pneumococcal meningitis model}

A well-characterized mouse model of pneumococcal meningitis was used in this study (25). Prior to infection, mice were weighed and scored clinically, and temperature was taken. For clinical scoring, different tasks were evaluated, namely a postural reflex test and a beam walk test. Additionally, clinical scoring comprised presence of seizures, piloerection, or reduced vigilance (57). The maximum clinical score was 12 and indicated severe disease, whereas a score of 0 defined healthy, uninfected mice. To further evaluate locomotor and exploratory behavior the OFT was used. In this test, mice were put in the center of a square box, subdivided into 9 fields. Mice were observed for 2 minutes, and the number of entered fields was counted. After clinical evaluation, bacterial meningitis was induced by intracisternal injection of $15 \mu \mathrm{l} 10^{7} \mathrm{CFUs}$ per $\mathrm{ml}$ S. pneumoniae type 2 (D39 strain; provided by Sven Hammerschmidt, University of Greifswald, Greifswald, Germany) under short-term anesthesia with isoflurane. To evaluate the acute disease, animals were investigated 24 hours after infection. To evaluate adjuvant treatment options, mice received antibiotic therapy (100 $\mathrm{mg} / \mathrm{kg}$ ceftriaxone i.p.) together with adjuvant treatment at 24 hours after infection and were investigated 48 hours after infection. In both settings, at the end of each experiment, animals were weighed and scored clinically as described above, and the temperature was taken. Mice were then anesthetized with ketamine/xylazine, and a catheter was placed into the cisterna magna. CSF samples were obtained for wbc count and determination of bacterial titers. ICP was measured. Finally, animals were perfused transcardially with ice-cold PBS, and brains were removed and either frozen immediately or fixed in formalin. Formalin-fixed brains were subsequently embedded in paraffin for immunohistochemistry.

\section{Experimental groups in the mouse model}

Acute model of pneumococcal meningitis. The following experimental groups were investigated: (a) WT mice injected intracisternally with $15 \mu \mathrm{l}$ PBS (controls; C57BL/6, male, $n=8$ and BALB/c, male, $n=6$ ); (b) WT mice injected intracisternally with $S$. pneumoniae (C57BL/6, male, $n=12$; C57BL/6, female, $n=20$; and BALB $/ c$, male, $n=10$ ); (c) C3arr $1^{-/-}$mice (male, genetic background C57BL/6; provided by Richard A. Wetsel, University of Texas Health Science Center, Houston, Texas, USA) injected intracisternally with $S$. pneumoniae $(n=12)$; (d) C3a/GFAP mice (male, genetic background C57BL/6) injected intracisternally with $S$. pneumoniae $(n=11)$; (e) $\mathrm{C6}^{-/-}$mice (female, genetic background C57BL/6) injected intracisternally with $S$. pneumoniae $(n=14)$; (f) $\mathrm{Cd}_{59 a^{-/-}}$mice (female, genetic background C57BL/6) injected intracisternally with $S$. pneumoniae $(n=11) ;(\mathrm{g}) \mathrm{C}_{\mathrm{arr}} \mathrm{1}^{-/}$mice (male, genetic background BALB/c, obtained from The Jackson Laboratory) injected intracisternally with $S$. pneumoniae $(n=9)$; (h) WT mice injected intracisternally with $S$. pneumoniae and treated i.p. with either a neutralizing monoclonal antibody directed against murine C5 (1 mg per mouse; clone BB5.1, $n=7)(58,59)$ or mouse IgG antibodies (1 mg per mouse, $n=12$; Innovative Research); (i) WT mice injected intracisternally with $S$. pneumoniae and treated i.p. with a neutralizing monoclonal antibody directed against murine C5 (30 $\mu$ g per mouse; clone BB5.1, $n=3$ ), i.t. with a neutralizing monoclonal antibody directed against murine C5 (30 $\mu \mathrm{g}$ per mouse; clone BB5.1, $n=4)$, or i.t. mouse IgG antibodies $(30 \mu \mathrm{g}$ per mouse, $n=4$ ); (j) WT mice injected intracisternally with $S$. pneumoniae and treated i.p. with $250 \mu \mathrm{g}$ anti-GR-1 (granulocyte depletion antibody; $n=8)$ or mouse IgG antibodies (250 $\mu$ g per mouse, $n=8)$; (k) WT mice injected intracisternally with $S$. pneumoniae and treated i.p. with a neutralizing monoclonal antibody directed against CXCL2/MIP-2 (100 $\mu \mathrm{g}$ per mouse, $n=3$ ), the neutralizing antibody against CXCL2/MIP-2 combined with a neutralizing antibody directed against CXCL1/KC (100 $\mu \mathrm{g}$ per mouse, $n=4)$, rat isotype control antibodies $\left(\operatorname{IgG}_{2 \mathrm{~B}} ; 100 \mu \mathrm{g}\right.$ per mouse, $n=3)$, or rat isotype control antibodies $\left(100 \mu \mathrm{g} \mathrm{IgG}_{2 \mathrm{~B}}\right.$ and $100 \mu \mathrm{g} \operatorname{IgG}_{2 \mathrm{~A}}$ per mouse, $n=4$ ); (l) WT mice injected intracisternally with $S$. pneumoniae and treated i.p. with a neutralizing monoclonal antibody directed against murine TLR2 and TLR4, clone T2.5 (mTLR2), and clone 1A6 (hTLR4) $(n=8)$ (provided by Novimmune) $(0.75 \mathrm{mg}$ each per mouse, $n=5)$ or mouse IgG antibodies (1.5 mg per mouse, $n=5$ ).

Treatment model of pneumococcal meningitis. WT mice were injected intracisternally with $S$. pneumoniae (C57BL/6, male) and additionally treated 
i.p. with (a) PBS (250 $\mu \mathrm{l}$ at 24 and 32 hours after infection; $n=16)$; (b) dexamethasone $(0.5 \mathrm{mg} / \mathrm{kg}$ at 24 and 32 hours after infection; $n=10)$; (c) a neutralizing monoclonal antibody directed against murine C5 (1 mg per mouse; clone BB5.1, $n=10)$; (d) neutralizing antibodies direct against TLR2 and TLR4 ( $0.75 \mathrm{mg}$ each per mouse; $n=8)$; and (e) mouse IgG antibodies ( $1 \mathrm{mg}$ per mouse; $n=21$ ).

\section{Determination of cerebellar bacterial titers}

For determination of bacterial titers, the cerebellum was dissected and homogenized in $1 \mathrm{ml}$ sterile PBS. Cerebellar homogenates were diluted serially, plated on blood agar plates, and cultured for 24 hours before CFUs were counted.

\section{Neuroscore}

For better comparison, the degree of breaching of the BBB integrity and the number of intracerebral hemorrhages were combined in a neuroscore. For the determination of the BBB integrity, frozen mouse brain extracts were examined for diffusion of albumin using ELISA as described previously (25). The score was 0,1 , or 2 , if brain albumin was $0-35,36-75$, or $76-140 \mathrm{ng} / \mu \mathrm{g}$, respectively. For more than $140 \mathrm{ng} / \mu \mathrm{g}$ of albumin, the score assigned was 3 . For determination of intracerebral hemorrhage, mouse brains were cut in a frontal plane into $10-\mathrm{mm}$ thick sections. Beginning from the anterior parts of the lateral ventricles, 9 serial sections were photographed with a digital camera at $0.3-\mathrm{mm}$ intervals throughout the ventricle system. Hemorrhagic spots were counted, and the bleeding area was measured. A score of 0 indicates no cerebral bleedings, a score of 1 indicates up to 20 cerebral bleeding spots, a score of 2 indicates between 21 and 60 cerebral bleeding spots, and a score of 3 indicates more than 60 cerebral bleeding spots. The maximum neuroscore was 6 and indicated severe neuronal damage, whereas a score of 0 indicated no neuronal damage.

\section{Analysis of protein expression}

Expression of C5a, TCC, IL-6, CXCL1/KC, and CXCL2/MIP-2 was determined in mouse brain homogenates by ELISA according to the manufacturer's instructions (C5a and TCC, USCN Life Science, Biozol; IL-6, CXCL2/MIP-2, and CXCL1/KC, R\&D Systems). Expression profiles of $\mathrm{C} 5 \mathrm{a}$ and TCC were additionally evaluated by immunohistochemistry performed on paraffin-embedded slides of mouse brain tissue as previously described (60). Briefly, after deparaffinization and steam bath antigen retrieval in citrate buffer, endogenous peroxidase was quenched with $7.5 \%$ hydrogen peroxide. Nonspecific binding was minimized by incubation in $10 \%$ normal goat serum. Slides were then incubated overnight at $4^{\circ} \mathrm{C}$ with a rat anti-mouse C5a or TCC antibody or the appropriate isotype control immunoglobulin. Specific labeling was detected with a biotin-conjugated rabbit anti-rat antibody and application of horseradish peroxidase-bound avidin/biotin from Vectastain ABC Kits, followed by development with 3,3'-diaminobenzidine (DAB) solution (both from Vector Laboratories). Counterstaining was performed using Mayer's hematoxylin. Slides were digitized using a Zeiss Axiovert microscope (Carl Zeiss) connected to a cooled Moticam 5000 video camera (Moticam).

\section{Statistical analysis - genetic analysis}

For evaluating the role of SNPs on outcome, assuming an overall event rate of $25 \%$ ( $n=100$ cases) to patients with favorable outcome $(n=300)$, a sample size of 400 provides sufficient power $(80 \%)$ when a risk genotype has a relative risk of 3.0 or more, using a $P$ value of 0.0029 (Bonferroni corrected).
The Mann-Whitney $U$ test was used to identify differences in baseline characteristics among groups with respect to continuous variables, and dichotomous variables were compared with use of the $\chi^{2}$ test. These statistical tests were 2 -tailed, and a $P$ value of less than 0.05 was regarded as significant. Differences in genotype frequencies were analyzed with the $\chi^{2}$ or Fishers' exact tests by use of the programs R-statistics and PASW18. For the SNP analysis, we used a Bonferroni correction for multiple testing (17 SNPs; $P<0.0029)$. We calculated whether the genotype frequencies in the control groups concurred with the HWE by use of a $\chi^{2}$ and exact test with 1 degree of freedom with a $P$ value of less than 0.05 to indicate significance. SNPs deviating from the HWE were excluded.

The genotype frequencies of patients with a favorable outcome was compared with those with an unfavorable outcome as defined by the GOS. Subgroup analyses were defined by ethnicity (mixed European descent), causative organism (S. pneumoniae), and a combination of these factors. We used a multivariate logistic regression analysis to calculate ORs and $95 \%$ CIs to assess the strength of the association among potential risk factors (including identified polymorphisms) and outcome.

\section{Statistics - animal experiments}

The principal statistical test was a 2-tailed unpaired Student's $t$ test (combined with an $\alpha$-adjustment in case of multiple comparisons) or a logrank test (Mantel) for survival. Differences were considered significant at $P<0.05$. Data are displayed as mean \pm SD.

\section{Study approval}

The protocol used in this study was approved by the Academic Medical Center and all local participating hospitals (see Supplemental Methods). Written informed consent was obtained from all participating patients, or their legally authorized representatives, and controls. All animal experiments were approved by the animal ethic committee of the government of Upper Bavaria, Germany.

\section{Acknowledgments}

This study has been funded by grants from the Netherlands Organization for Health Research and Development (ZonMw; NWO-Veni grant 2006 [916.76.023] and NWO-Vidi grant 2010 [917.113.58] to D. van de Beek), the Academic Medical Center (AMC Fellowship 2008 to D. van de Beek), the European Research Council (ERC Starting Grant 281156 to D. van de Beek), the German Research Foundation (Pfi246/7-1 to H.W. Pfister and U. Koedel and SFB-576, TP-A5 to U. Koedel), and the Else Kröner Fresenius Stiftung (P72/08 // A84/08 to U. Koedel). We thank B. Angele for her technical assistance and Sven Hammerschmidt, University of Greifswald, Germany, for providing pneumococcal strains. We thank M.T. van Meegen and E. Jansen for their work on genotyping. We thank the Dutch physicians that participated in the study (see Supplemental Methods).

Received for publication February 9, 2011, and accepted in revised form August 3, 2011.

Address correspondence to: Diederik van de Beek, Department of Neurology, Center of Infection and Immunity Amsterdam (CINIMA), Academic Medical Center, University of Amsterdam, PO Box 22660, 1100DD Amsterdam, The Netherlands. Phone: 31205663842; Fax: 31205669374; E-mail: D.vandeBeek@amc.uva.nl.
1. Brouwer MC, Tunkel AR, van de Beek D. Epidemiology, diagnosis, and antimicrobial treatment of acute bacterial meningitis. Clin Microbiol Rev. 2010;23(3):467-492.
2. van de Beek D, de Gans J, Tunkel AR, Wijdicks EF. Community-acquired bacterial meningitis in adults. N Engl J Med. 2006;354(1):44-53.

3. van de Beek D, de Gans J, Spanjaard L, Weisfelt M,
Reitsma JB, Vermeulen M. Clinical features and prognostic factors in adults with bacterial meningitis. N Engl J Med. 2004;351(18):1849-1859.

4. Tauber MG, Khayam-Bashi H, Sande MA. Effects of 
ampicillin and corticosteroids on brain water content, cerebrospinal fluid pressure, and cerebrospinal fluid lactate levels in experimental pneumococ cal meningitis. J Infect Dis. 1985;151(3):528-534.

5. de Gans J, van de Beek D. Dexamethasone in adults with bacterial meningitis. N Engl J Med. 2002; 347(20):1549-1556.

6. van de Beek D, de Gans J. Dexamethasone in adults with community-acquired bacterial meningitis. Drugs. 2006;66(4):415-427.

7. van de Beek D, et al. Adjunctive dexamethasone in bacterial meningitis: a meta-analysis of individual patient data. Lancet Neurol. 2010;9(3):254-263.

8. Brouwer MC, McIntyre P, de Gans J, Prasad K, van de Beek D. Corticosteroids for acute bacterial meningitis. Cochrane Database Syst Rev. 2010;(9):CD004405.

9. Brouwer MC, Heckenberg SG, de Gans J, Spanjaard L, Reitsma JB, van de Beek D. Nationwide implementation of adjunctive dexamethasone therapy for pneumococcal meningitis. Neurology. 2010; 75(17):1533-1539

10. Hamburg MA, Collins FS. The path to personalized medicine. NEngl J Med. 2010;363(4):301-304.

11. Brouwer MC, de Gans J, Heckenberg SG, Zwinderman AH, van der Poll T, van de Beek D. Host genetic susceptibility to pneumococcal and meningococcal disease: a systematic review and meta-analysis. Lancet Infect Dis. 2009;9(1):31-44.

12. Ricklin D, Hajishengallis G, Yang K, Lambris JD. Complement: a key system for immune surveillance and homeostasis. Nat Immunol. 2010;11(9):785-797.

13. Jönsson G, Truedsson L, Sturfelt G, Oxelius VA, Braconier JH, Sjöholm AG. Hereditary C2 deficiency in Sweden: frequent occurrence of invasive infection, atherosclerosis, and rheumatic disease. Medicine (Baltimore). 2005;84(1):23-34.

14. Sprong T, et al. Deficient alternative complement pathway activation due to factor D deficiency by 2 novel mutations in the complement factor $\mathrm{D}$ gene in a family with meningococcal infections. Blood. 2006;107(12):4865-4870.

15. Biesma DH, et al. A family with complement factor D deficiency. J Clin Invest. 2001;108(2):233-240.

16. Fijen CA, et al. Properdin deficiency: molecular basis and disease association. Mol Immunol. 1999;36(13-14):863-867.

17. Haralambous E, et al. Factor $\mathrm{H}$, a regulator of complement activity, is a major determinant of meningococcal disease susceptibility in UK Caucasian patients. Scand J Infect Dis. 2006;38(9):764-771.

18. Davila S, et al. Genome-wide association study identifies variants in the $\mathrm{CFH}$ region associated with host susceptibility to meningococcal disease. Nat Genet. 2010;42(9):772-776.

19. Tuomanen E, Hengstler B, Zak O, Tomasz A. The role of complement in inflammation during experimental pneumococcal meningitis. Microb Pathog. 1986;1(1):15-32.

20. Paul R, et al. Myeloid Src kinases regulate phagocytosis and oxidative burst in pneumococcal meningitis by activating NADPH oxidase. J Lenkoc Biol. 2008;84(4):1141-1150.

21. Rupprecht TA, et al. Complement $\mathrm{C} 1 \mathrm{q}$ and $\mathrm{C} 3$ are critical for the innate immune response to Streptococcus pneumoniae in the central nervous system. J Immunol. 2007;178(3):1861-1869.

22. Gardner P. Clinical practice. Prevention of meningococcal disease. $N$ Engl J Med. 2006; 355(14):1466-1473.

23. Jennett B, Teasdale G, Braakman R, Minderhoud J, Knill-Jones R. Predicting outcome in individual patients after severe head injury. Lancet. 1976; 1(7968):1031-1034.

24. Weisfelt M, van de Beek D, Spanjaard L, Reitsma JB, de Gans J. Clinical features, complications, and outcome in adults with pneumococcal meningitis: a prospective case series. Lancet Neurol. 2006; 5(2):123-129.

25. Koedel U, et al. Apoptosis is essential for neutrophil functional shutdown and determines tissue damage in experimental pneumococcal meningitis. PLoS Pathog. 2009;5(5):e1000461.

26. Brown JS, et al. The classical pathway is the dominant complement pathway required for innate immunity to Streptococcus pneumoniae infection in mice. Proc Natl Acad Sci US A. 2002;99(26):16969-16974.

27. Koedel U, Klein M, Pfister HW. New understandings on the pathophysiology of bacterial meningitis. Curr Opin Infect Dis. 2010;23(3):217-223.

28. Boos L, Campbell IL, Ames R, Wetsel RA, Barnum SR. Deletion of the complement anaphylatoxin C3a receptor attenuates, whereas ectopic expression of C3a in the brain exacerbates, experimental autoimmune encephalomyelitis. J Immunol. 2004; 173(7):4708-4714.

29. Klein $M$, et al. Innate immunity to pneumococcal infection of the central nervous system depends on toll-like receptor (TLR) 2 and TLR4. J Infect Dis. 2008; 198(7):1028-1036.

30. Tunkel AR, et al. Practice guidelines for the management of bacterial meningitis. Clin Infect Dis. 2004; 39(9):1267-1284.

31. Armstrong PW, et al. Pexelizumab for acute STelevation myocardial infarction in patients undergoing primary percutaneous coronary intervention: a randomized controlled trial. JAMA. 2007; 297(1):43-51

32. Hillmen P, et al. The complement inhibitor eculizumab in paroxysmal nocturnal hemoglobinuria. N Engl J Med. 2006;355(12):1233-1243.

33. Weisfelt M, van de Beek D, Spanjaard L, Reitsma JB, de Gans J. Attenuated cerebrospinal fluid leukocyte count and sepsis in adults with pneumococcal meningitis: a prospective cohort study. BMC Infect Dis. 2006;6:149

34. Giampaolo C, Scheld M, Boyd J, Savory J, Sande M, Wills M. Leukocyte and bacterial interrelationships in experimental meningitis. Ann Neurol. 1981; 9(4):328-333.

35. Tauber MG, Kennedy SL, Tureen JH, Lowenstein DH. Experimental pneumococcal meningitis causes central nervous system pathology without inducing the 72-kd heat shock protein. Am J Pathol. 1992; 141(1):53-60

36. Tortajada A, Montes T, Martinez-Barricarte R, Morgan BP, Harris CL, de Cordoba SR. The diseaseprotective complement factor $\mathrm{H}$ allotypic variant Ile62 shows increased binding affinity for C3b and enhanced cofactor activity. Hum Mol Genet. 2009; 18(18):3452-3461.

37. Goicoechea de JE, et al. Gain-of-function mutations in complement factor B are associated with atypical hemolytic uremic syndrome. Proc Natl Acad Sci U S A. 2007;104(1):240-245.

38. Hillebrandt $\mathrm{S}$, et al. Complement factor 5 is a quantitative trait gene that modifies liver fibrogenesis in mice and humans. Nat Genet. 2005;37(8):835-843.

39. Gressner O, et al. Gc-globulin concentrations and C5 haplotype-tagging polymorphisms contribute to variations in serum activity of complement factor C5. Clin Biochem. 2007;40(11):771-775.

40. Ernst JD, Hartiala KT, Goldstein IM, Sande MA. Complement (C5)-derived chemotactic activity accounts for accumulation of polymorphonuclear leukocytes in cerebrospinal fluid of rabbits with pneumococcal meningitis. Infect Immun. 1984; 46(1):81-86.

41. Kadurugamuwa JL, Hengstler B, Bray MA, Zak O. Inhibition of complement-factor-5a-induced inflammatory reactions by prostaglandin E2 in experimen- tal meningitis. J Infect Dis. 1989;160(4):715-719.

42. Tuomanen EI, Saukkonen K, Sande S, Cioffe C, Wright SD. Reduction of inflammation, tissue damage, and mortality in bacterial meningitis in rabbits treated with monoclonal antibodies against adhesion-promoting receptors of leukocytes. J Exp Med. 1989;170(3):959-969.

43. Ritis K, et al. A novel C5a receptor-tissue factor crosstalk in neutrophils links innate immunity to coagulation pathways. JImmunol. 2006;177(7):4794-4802.

44. Markiewski MM, Nilsson B, Ekdahl KN, Mollnes TE, Lambris JD. Complement and coagulation: strangers or partners in crime? Trends Immunol. 2007; 28(4):184-192.

45. Leung LL, Myles T, Nishimura T, Song JJ, Robinson WH. Regulation of tissue inflammation by thrombin-activatable carboxypeptidase B (or TAFI). Mol Immunol. 2008;45(16):4080-4083.

46. Vergouwen MD, Schut ES, Troost D, van de Beek D. Diffuse cerebral intravascular coagulation and cerebral infarction in pneumococcal meningitis. Neurocrit Care. 2010;13(2):217-227

47. Kastenbauer S, Pfister HW. Pneumococcal meningitis in adults: spectrum of complications and prognostic factors in a series of 87 cases. Brain. 2003; 126(pt 5):1015-1025.

48. Jacob A, Hack B, Chiang E, Garcia JG, Quigg RJ, Alexander JJ. C5a alters blood-brain barrier integrity in experimental lupus. FASEB J. 2010;24(6):1682-1688.

49. Liu ZM, et al. Silencing of C5a receptor gene with siRNA for protection from Gram-negative bacterial lipopolysaccharide-induced vascular permeability. Mol Immunol. 2010;47(6):1325-1333.

50. Farkas I, Baranyi L, Liposits ZS, Yamamoto T, Okada H. Complement C5a anaphylatoxin fragment causes apoptosis in TGW neuroblastoma cells. NeuroScience. 1998;86(3):903-911.

51. Yanamadala V, Friedlander RM. Complement in neuroprotection and neurodegeneration. Trends Mol Med. 2010;16(2):69-76.

52. Sprong $\mathrm{T}$, et al. Inhibition of $\mathrm{C} 5 \mathrm{a}$-induced inflammation with preserved C5b-9-mediated bactericidal activity in a human whole blood model of meningococcal sepsis. Blood. 2003;102(10):3702-3710.

53. Brouwer MC, Read RC, van de Beek D. Host genetics and outcome in meningococcal disease: a systematic review and meta-analysis. Lancet Infect Dis. 2010; 10(4):262-274.

54. Woodruff TM, et al. Antiarthritic activity of an orally active $\mathrm{C} 5 \mathrm{a}$ receptor antagonist against antigeninduced monarticular arthritis in the rat. Arthritis Rheum. 2002;46(9):2476-2485.

55 . Vergunst CE, et al. Blocking the receptor for C5a in patients with rheumatoid arthritis does not reduce synovial inflammation. Rheumatology (Oxford). 2007; 46(12):1773-1778.

56. Osmers I, Szalai AJ, Tenner AJ, Barnum SR. Complement in $\mathrm{BuB} / \mathrm{BnJ}$ mice revisited: serum $\mathrm{C} 3$ levels and complement opsonic activity are not elevated. Mol Immunol. 2006;43(10):1722-1725.

57. Malipiero U, et al. TGFbeta receptor II gene deletion in leucocytes prevents cerebral vasculitis in bacterial meningitis. Brain. 2006;129(pt 9):2404-2415

58. Huugen D, et al. Inhibition of complement factor C5 protects against anti-myeloperoxidase antibody-mediated glomerulonephritis in mice. Kidney Int. 2007;71(7):646-654.

59. de Vries B, Matthijsen RA, Wolfs TG, van Bijnen AA, Heeringa P, Buurman WA. Inhibition of complement factor C5 protects against renal ischemiareperfusion injury: inhibition of late apoptosis and inflammation. Transplantation. 2003;75(3):375-382.

60. Kastenbauer S, Koedel U, Becker BF, Pfister HW. Oxidative stress in bacterial meningitis in humans. Neurology. 2002;58(2):186-191. 